\title{
Inventores prolíficos, conocimiento tecnológico y patentes: México y Corea
}

\author{
Isabel López Escobedo*
}

\section{RESUMEN}

La reflexión económica sobre la importancia de la producción de nuevo conocimiento como factor estratégico para el crecimiento y el desarrollo tecnológico, y la función que desempeñan los inventores prolíficos en las economías como agentes clave en el proceso de innovación, constituyen los temas centrales de este artículo. Se estudia a los inventores prolíficos como agentes dinámicos en la producción de nuevas ideas y como gestores tecnológicos que estimulan a los grupos de investigación en los que participan al registrar un notorio aumento de sus patentes. Se analiza comparativamente el grado de las patentes de los inventores prolíficos de México y Corea durante el periodo 1978-2006, identificando a los que más lo hacen y los campos tecnológicos en los que éstos se especializan.

Número de clasificación:

Palabras clave: economía del conocimiento, inventores prolíficos, conocimiento tecnológico, patentes, innovación.

\begin{abstract}
The economic reflection on the importance of the production of new knowledge as a strategic factor for growth and technological development, and the role of prolific inventors in the economies, such as key agents in the process of innovation, constitute the central themes of this article. It is being studied to prolific inventors as dynamic agents in the production of new ideas and as managers technological that to further research groups in those involved, to register a notable increase in patenting. Analyzes comparatively the degree of patenting of prolific inventors of Mexico and Korea during the period 19782006, identifying the most patentees and technological fields in which these specialize.
\end{abstract}

\section{Clasification number:}

Key words: economics knowledge, prolific inventors, technological knowledge, patents, innovations.

\footnotetext{
* Maestra en Economía y Gestión de la Innovación, Universidad Autónoma Metropolitana Unidad Xochimilco [isagu77@yahoo.com.mx]
} 


\section{INTRODUCCIÓN}

El trabajo de C. Gay, W. Latham y C. Le Bas ${ }^{1}$ (2005) sirve como antecedente para el desarrollo de este artículo. ${ }^{2}$ Los autores analizan la importancia de los inventores como agentes clave en la producción de conocimiento, con una activa participación en el proceso de patentes. Introducen en la bibliografía el concepto de inventores prolificos (IP) "considerados agentes que inventan constantemente y tienen una alta participación en el proceso de creación de nuevas ideas". Este concepto cobra relevancia al reflexionar sobre su participación estratégica en el aceleramiento del proceso de innovación, señalando que "dentro de las empresas, la producción de conocimiento es resultado de múltiples intercambios entre agentes, no sólo en actividades de ID, sino también en la movilización del trabajo de equipo y las relaciones profesionales".

Si bien el proceso de innovación puede entenderse como la transformación de un producto de forma cuantitativa o radical, ésta también puede comprenderse como la capacidad de producir, gestionar, utilizar y transferir de forma eficiente el conocimiento tecnológico y adaptarlo a nuevos contextos y formas de hacer y de pensar. La contribución de los inventores al proveer de nuevas ideas tiene un efecto positivo en la construcción del acervo de conocimientos de las economías, lo cual puede expresarse en un incremento de los registros de patentes, resultado de su activa participación en la producción de valor.

La formación del acervo de conocimientos y el fortalecimiento de las capacidades centrales de los IP de una economía en particular, dependerá de alcanzar un mayor grado de educación y especialización, con la finalidad de cerrar la brecha tecnológica existente entre los países desarrollados y en desarrollo.

La aportación del presente trabajo consiste en sugerir que una posible explicación del rezago tecnológico de México respecto a Corea puede estar asociado con la baja participación de inventores mexicanos en actividades de ID vinculadas con el registro de patentes, resultando en una baja producción de conocimiento tecnológico.

\footnotetext{
${ }^{1}$ En su estudio, el fenómeno de la participación de agentes clave, inventores prolíficos fue desarrollado para países industrializados: Alemania, Francia y Reino Unido, 1975-1999.

${ }^{2}$ Investigación que sirvió como antecedente para el desarrollo de la tesis de maestría de la autora. Tesis denominada: "Inventores prolíficos en la producción de nuevo conocimiento: un estudio comparativo entre México y Corea a través de patentes de Estados Unidos (USPTO) 19782006".
} 
El eje central del artículo se compone de los siguientes aspectos:

a) Reflexionar sobre las características de los IP y el conocimiento que poseen.

b) Explicar por qué las patentes representan un indicador indirecto (proxy) de la actividad inventiva y de la creatividad de los IP, además de ser importantes acervos de información y conocimiento tecnológico. ${ }^{3}$

c) Identificar a los IP más dinámicos de México y Corea, reconocidos por su grado de participación en registro de patentes, ${ }^{4}$ en el periodo que abarca de 1978 a 2006 consignado por la Oficina de Patentes y Marcas Registradas de Estados Unidos (USPTO, por sus siglas en inglés). ${ }^{5}$

d) Analizar los campos tecnológicos en los que se especializan los IP, como una manera de conocer el patrón tecnológico dentro del cual se han desarrollado economías como México y Corea.

El artículo está organizado en cuatro secciones. La sección I revisa brevemente la bibliografía que pone el acento en el papel que desempeñan los IP en el proceso de innovación tecnológica. Asimismo, se plantea con mayor precisión la definición y algunas características que describen a los inventores clave. En la sección II se señala la importancia de las patentes como indicador proxy de la actividad inventiva, y el criterio de selección con el cual fueron identificados los IP. La sección III se subdivide en dos partes. En la primera se muestran los nombres de los IP de México y Corea que más han patentado durante el periodo antes mencionado. En la segunda se estudia el ritmo de registros de patentes de los IP y su orientación tecnológica. Al final, en la sección IV, se presentan las reflexiones finales.

${ }^{3}$ El conocimiento contenido en las patentes es principalmente tecnológico. La relevancia de la información que existe en ellas radica en: $a$ ) describir tecnologías, procedimientos o productos orientados a aplicaciones concretas, $b$ ) conocer lo novedoso y temprano de nuevas líneas de ID, c) ser fuente de ideas y conocimiento, $d$ ) facilitar una visión del contexto inventivo, es decir, del estado del arte (nivel de desarrollo de las tecnologías: maduras o de punta para descubrir nuevos nichos de mercado).

${ }^{4}$ Contribución en múltiples patentes que los hace distinguirse del conjunto de inventores de una economía.

${ }^{5}$ United States Patent and Trademark Office, en: http://www.uspto.gov. Su función es la concesión de patentes para la protección de las invenciones y el registro de marcas. Orienta sus funciones al servicio de los intereses de los inventores y de las empresas respecto a sus invenciones y productos corporativos por medio de la preservación, clasificación y difusión de la información sobre patentes. 


\section{REFLEXIÓN SOBRE EL VALOR DE LOS INVENTORES EN EL PROCESO DE INNOVACIÓN}

Las revoluciones tecnológicas ${ }^{6}$ y el ritmo acelerado de los flujos de información han estimulado la creación de un entorno global que exige el uso eficiente del conocimiento tecnológico en diversos ámbitos (educativo, organizacional, empresarial y comercial, etcétera), derivado del contexto de incertidumbre en el que actualmente se desarrolla el proceso de cambio técnico. ${ }^{7}$ Lo anterior demanda el fortalecimiento de las capacidades de aprendizaje y de especialización de los agentes económicos. Autores como Dogson (1993, p. 380) señalan que "las rutinas de aprendizaje sirven como mecanismo de adaptación y ajuste que permite a los agentes y a las empresas sobrevivir dentro del ambiente incierto y competitivo".

Las actuales economías del conocimiento están contemplando la emergencia de nuevos paradigmas para la innovación y el avance del conocimiento en relación con la producción económica. El argumento de Romer (1990) en relación con el cambio técnico que han sufrido las economías indica que: "las materias primas que usamos no han cambiado, pero las instrucciones que seguimos para combinarlas se han tornado mucho más refinadas a resultas de la experiencia, la experimentación, la educación y la investigación científica”, fundamentando que en un cambio de paradigma, los agentes económicos se preocupan por invertir no en capital tangible y perecedero (propiedades, máquinas y acumulación de inventarios, etcétera), sino más bien en capital intangible como el conocimiento, capaz de ser empleado al mismo tiempo en diversos contextos por una gran cantidad de agentes y con la cualidad de ser transferible y acumulable.

El eje fundamental de esas economías son la generación de ideas novedosas, el impulso de la creatividad, el uso eficiente de la información y la producción de valor (producción de nuevo conocimiento), lo cual es provisto por el $\mathrm{ca}$ pital intelectual (inventores, investigadores, gestores, etcétera) de que disponen

\footnotetext{
${ }^{6}$ Una revolución tecnológica es "un poderoso y visible conjunto de tecnologías, productos e industrias nuevas y dinámicas, capaces de sacudir los cimientos de la economía y de impulsar una oleada de desarrollo de largo plazo. Es una etapa que da como resultado un proceso de acumulación del conocimiento y del saber hacer" (Pérez, 2004, p. 33).

${ }^{7}$ La dirección del cambio técnico (la trayectoria tecnológica) está determinada conjuntamente por el estado del arte, la especulación del ambiente y las tecnologías que poseen las empresas. El descubrimiento de nuevas tecnologías (adecuadas a un entorno particular) surge no sólo en el mercado, sino además, fuera de las condiciones de equilibrio donde los agentes hacen más que ajustar los precios a las cantidades y viceversa, en el sentido de que toda acumulación de conocimientos (vista como una innovación $=$ patente) puede transformar el entorno interno y externo en que se desarrolla.
} 
las naciones. Los conocimientos producidos por parte de los inventores han cobrado gran relevancia, por un lado, como fuente para la producción de nuevos conocimientos y, por otro, como importantes insumos para la generación de futuras innovaciones.

En ese sentido, el estudio de los IP permite indagar sobre su función en el proceso de innovación, al pensarlos como agentes clave en la producción de nuevas ideas y como gestores tecnológicos que impulsan a los grupos de investigación en los que participan a tener un registro de patentes significativo.

La reflexión económica cobra relevancia en dos sentidos: $a$ ) identificar cuáles son los mecanismos institucionales o marcos regulatorios eficientes, de los que en buena medida dependen los incentivos que promuevan ambientes propicios para la innovación, y $b$ ) cuestionar la función que desempeñan los inventores en las organizaciones y en las economías, en tanto agentes capaces de producir nuevo conocimiento tecnológico, como estrategia para tornarlas más competitivas. En este último punto se pone el énfasis de este artículo.

$\mathrm{El}$ argumento central considera que los IP son agentes clave para impulsar el crecimiento económico y el cambio tecnológico debido a: i) el conocimiento que poseen, $i i$ ) sus capacidades individuales para producir conocimiento, y iii) que sobre todo, son gestores y promotores de grupos de ID que impulsan la producción de nuevo conocimiento tecnológico dentro de las empresas en una economía específica. Darby y Zucker (1996, p. 4) afirman que "el rol de los científicos es fundamental no sólo en el proceso de innovación tecnológica sino también en la producción de valor y en la dirección de grupos"; por su parte, Mangematin et al. (2003), aseveran que "la superioridad de los IP es el resultado no sólo del conocimiento (en gran parte tácito y especializado) que poseen, sino también de sus capacidades empresariales".

En su estudio, C. Gay et al. (2005, p. 16) están de acuerdo con que el enfoque de la economía del conocimiento estudia "los efectos del funcionamiento de los mercados y los procesos de producción, en lo que se refiere a los requerimientos y producción de conocimiento, y al comportamiento de las empresas en su capacidad de acumular competencias, tales como el conocimiento integrador de sistemas, es decir, al IP capaz de coordinar la competencia y capacidad de los miembros del equipo de investigación, con la finalidad de aumentar el rendimiento de las empresas tecnológicas y su competitividad económica".

La preocupación económica y empresarial actual reconoce la importancia de los inventores dentro de las empresas y la industria en general. Lo que les confiere valor es su capacidad para transferir sus ideas, experiencias y conoci- 
miento a las actividades productivas y de gestión, convirtiéndose en un insumo estratégico no sólo para la producción de nuevos procesos y productos, sino para la creación de nuevas ideas y conocimientos. Por tanto, innovar ya no sólo es transformar un producto (cuantitativa o radicalmente), también se relaciona con la capacidad de interactuar y converger con otras ideas y formas de organización que resulten en un aumento del potencial creativo de los inventores donde el IP es un agente clave.

Existe un cambio fundamental en la función de los agentes en la economía. Anteriormente, la inserción en la industria se daba por el total de horas que un trabajador estaba dispuesto a destinar a determinada actividad productiva (renunciar a horas de ocio), sin embargo, dentro del nuevo paradigma en que el conocimiento es un insumo estratégico, para formar parte de una comunidad (científica, tecnológica o empresarial) se requiere de un alto grado de aprendizaje y especialización que permita la imitación, adaptación y creación de nuevo conocimiento. Al respecto, David y Foray $(2003$, p. 8) señalan que "la mejora en la calidad del equipo físico y del capital humano representa una mejor explicación a ese fenómeno, es decir, a la creación de nuevos conocimientos y nuevas ideas y su incorporación al equipo físico y a las personas".

Así, la transición de las escalas productivas de los países ha venido acompañada de un fuerte desarrollo de las actividades de aprendizaje y de las capacidades cognitivas de los agentes que las integran, y de la manera en que los inventores se encuentran estrechamente relacionados con el proceso de innovación. Existe una transición de una etapa de control (taylorista) ${ }^{8}$ a un contexto en el que las formas de actuación y de participación son más flexibles, promueven la creatividad de los agentes y fortalecen su capacidad inventiva.

La creación de nuevas tecnologías no puede ser entendida como un hecho fortuito, sino más bien como un fenómeno asociado al contexto de esfuerzos institucionales, inversión en ID y ambientes cooperativos de aprendizaje que estimulan y definen el contexto para la innovación. Romer (1986) plantea que "las empresas al acumular capital intangible, acumulan al mismo tiempo conocimientos (aprendizaje), es decir, una medida aproximada del 'aprendizaje adquirido' o 'experiencia adquirida' durante el proceso de producción pasado, y así, debido a

8 "El taylorismo con su concepción instrumental del hombre y su énfasis en los procesos de análisis dividía al hombre en partes separando las funciones intelectuales, organizativas, creativas, de las habilidades manuales. Se rompe así con los métodos de producción del pasado en los cuales el artesano creaba, organizaba y completaba la producción. La creatividad del empleado se inhibía bajo el peso de un trabajo sobresimplificado, mecánico y rutinario" (Rojas, 2007). 
la circulación de información, otras empresas obtienen beneficios de dichos conocimientos", por lo que la estructura económica, debido a su composición de relaciones aleatorias y no unívocas, genera diversos escenarios que pueden derivar en distintos grados de difusión del conocimiento reformulando una y otra vez la recombinación de los factores que promueven la innovación.

En resumen, el conocimiento que poseen las empresas y los individuos provee a éstos de un estatus de poder y de movilidad que les permite internacionalizarse y tener acceso a otro tipo de comunidades de inventores e insertarse en distintas áreas del saber; además de que quien posee el conocimiento tiene en sí la destreza de administrarlo e invertirlo. Esas "comunidades se caracterizan por tres elementos: a) capacidades múltiples de creación y reproducción de conocimientos; $b$ ) mecanismos de intercambio y de circulación de los conocimientos creados, y $c$ ) la utilización intensiva de las nuevas tecnologías" (David y Foray, 2003, p. 15).

\section{Características de los IP}

C. Gay et al. (2005, p. 16) conciben la idea de que un inventor prolífico puede actuar como un "sistema integrador de conocimiento". En el contexto de la generación de conocimientos tecnológicos, el IP pretende coordinar la competencia y capacidad de los miembros del equipo con el fin de aumentar el rendimiento de las empresas tecnológicas y su competitividad económica. Parece que la manera en la que son codificados su conocimiento tácito (en relación con su capacidad especial para integrarse) y su gestión es decisiva para el desempeño de las empresas.

La definición de inventores prolíficos remite a aquellos agentes que participan en grupos de ID inventando constantemente, siendo individuos fundamentales en el proceso de creación de nuevas ideas con una dinámica participación en la actividad de registro de patentes que los diferencia de los demás participantes del equipo de investigación, pero que los vuelve agentes clave en el proceso de gestión del conocimiento (figura 1). Como lo define Vegara (1985, p. 153): “el empresario es aquel que busca la novedad, que extrae satisfacción de ella, de la innovación; el empresario es quien rompió con las resistencias de la novedad - Schumpeter - y halla una gratificación en esa actividad".

La creatividad de los IP es una característica decisiva en el proceso de invención. Antonelli et al. (2002, p. 17) explican que "el conocimiento se vuelve un intermediario de entrada que, después de la recombinación adecuada y el uso creativo, se convierte en un componente del proceso de producción que provee de 
Figura 1. Características del inventor prolífico

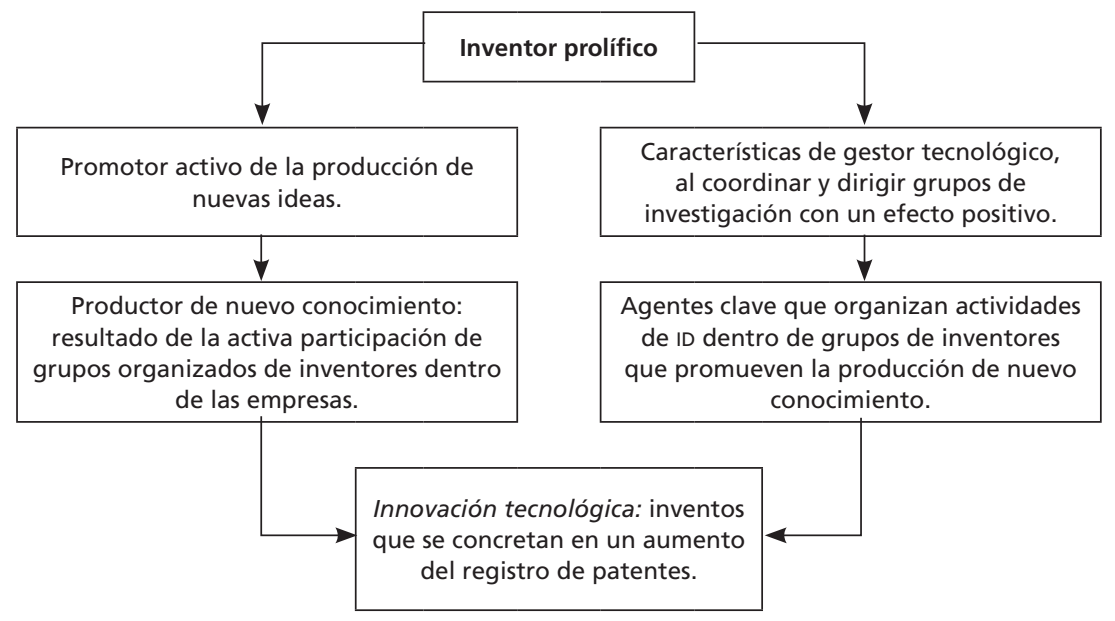

Fuente: Elaboración propia a partir de C. Gay et al. (2005).

nuevos conocimientos". Para Howell y Boies (2004, p. 128), "la creatividad es el punto de partida para la innovación y es en muchos casos un proceso solitario; pero la innovación es el trabajo duro que sigue a la concepción de la idea y a menudo implica la labor de muchos agentes con habilidades diversas aunque complementarias. Lo trascendental está en transformar las ideas creativas en productos tangibles o en procesos que mejoren los productos y servicios existentes, disminuyan los costos o generen nuevas ganancias a las empresas".

La capacidad de inventiva actúa, por un lado, como un impulso que promueve la capacidad para proyectar el futuro (para identificar el éxito de la innovación) y, por otro, como la capacidad de plantear objetivos en un plan de acción en conjunto (soluciones originales a problemas técnicos planteados dentro de comunidades de inventores). En el caso de México, la escasa cultura del riesgo y los pocos estímulos de las instituciones para promover e incentivar al capital intelectual podrían sugerir una de las causas del detrimento de la creatividad de los inventores e, incluso, del bajo registro de sus inventos (patentes) debido a la poca credibilidad y confianza generada por el ambiente de incertidumbre en el cual se desarrollan las actividades vinculadas con la tecnología.

En resumen, la capacidad de gestión, promoción y participación de los IP en la producción de nuevas ideas (dentro de grupos de ID), finalmente concretada en un aumento del registro de patentes, sugiere que la existencia de estos agentes puede tornar más competitivas a las naciones. El éxito de la innovación, "no sólo 
es resultado del uso eficiente de los recursos, la optimización de costos, ni de la intrínseca acumulación de conocimientos tácitos y especializados que adquieren los agentes a través de sus experiencias, sino de la notoria participación de los agentes clave dentro de la producción, en la promoción de nuevas ideas, formas de trabajo y desempeño de sus capacidades" (Howell y Boies, 2004, p. 130), también "es el resultado de las capacidades empresariales que los agentes poseen, lo que les permite ejecutar de forma eficiente todas las etapas encaminadas a la creación de un producto novedoso" (Mangematin et al., 2003, p. 625). Y "estas élites científicas y tecnológicas son activas no sólo en la producción y difusión de conocimientos, sino también en la identificación del éxito tecnológico" (C. Gay et al., 2005, p. 5).

Se considera que la actividad de los IP tiene un efecto positivo en la construcción del acervo de información y conocimientos de las economías, lo cual puede reflejarse en un incremento del registro de nuevas ideas, es decir, en un aumento del registro de patentes, resultado de su activa participación en la producción de valor. En este marco las patentes, como indicador indirecto de la actividad inventiva (y de la creatividad de los inventores), permitirían reconocer parámetros del nivel de desarrollo del proceso de innovación de una economía.

\section{PATENTES: INDICADOR PROXY DE LA ACTIVIDAD INVENTIVA DE LOS IP}

Las patentes son utilizadas como un proxy de la actividad inventiva desarrollada por los IP, además de representar un valioso acervo de información tecnológica y un insumo estratégico de la producción de nuevo conocimiento. El objetivo es explicar cómo este instrumento de propiedad intelectual permite distinguir a los agentes innovadores (IP) y conocer el patrón de registro de patentes y las áreas tecnológicas en las que se especializan mediante la construcción y diseño de bancos de datos de patentes.

\section{Criterio de comparación}

La selección de los países a estudiar se hizo con el siguiente criterio: se compara a México con Corea debido a que el país latinoamericano guarda una estrecha semejanza con el país asiático en el modelo económico inicial de industrialización (años setenta y mediados de los ochenta). Sin embargo, en las últimas décadas Corea registró un significativo proceso de industrialización y una notoria actividad innovadora, medida por su registro de patentes en Estados Unidos 
(USPTO), abriendo una brecha significativa con países en desarrollo como México. En la actualidad, Corea mantiene una importante producción de nuevos conocimientos registrados en patentes, semejante a la de países industrializados como Alemania, Francia y Reino Unido.

\section{Relevancia de las patentes como indicador tecnológico}

La patente es el carácter legal de un invento ${ }^{9}$ que concede a quien lo crea un monopolio temporal con la finalidad de ser explotado económicamente, y que al final de éste puede ser un importante acervo de conocimiento con impacto positivo en futuras innovaciones. Cárdenas (1997, p. 19) define la patente como "un monopolio otorgado por el Estado a un inventor por un periodo limitado de tiempo, en recompensa por la descripción de la invención, de tal manera que otros puedan gozar de su beneficio"; Aboites y Soria (1999, p. 35) la refieren como un "derecho exclusivo (monopolio) otorgado por el Estado para explotar (producir, usar o vender) durante un periodo determinado, una invención de producto o de proceso que reúne los siguientes requisitos: $i$ ) novedosa, ii) de aplicabilidad industrial, y iii) no obvia respecto al estado del arte previo".

$\mathrm{Su}$ importancia ${ }^{10}$ radica en que estos registros representan: $i$ ) un acervo potencial de conocimiento; ii) un insumo para la producción de nuevo conocimiento; iii) sistemas de información públicos que permiten el libre acceso a información uniforme y estructurada, accediendo al conocimiento de las áreas tecnológicas o científicas hacia las que se orientan los esfuerzos de ID de las economías; iv) el estado del arte o la técnica; v) un acervo donde reconocer a los investigado-

\footnotetext{
${ }^{9}$ Invento: hallazgo y aplicación práctica (por primera vez), de nuevas propiedades o instrumentos para nuevas necesidades y que de acuerdo con lo dispuesto por el artículo 22 de la Ley de Propiedad Industrial, debe cumplir con tres requisitos: ser novedoso, presentar actividad inventiva no conocida y tener aplicación industrial. Por su parte, una innovación puede entenderse como un invento comercializable, con difusión en el mercado.

10 "Tradicionalmente la búsqueda de información sobre patentes se efectuaba únicamente para los fines de redacción de su solicitud o para planear y preparar un litigio. Últimamente, esa información utilizada en el nivel micro ha ido evolucionando y ha llegado a ser más estratégica gracias a la creación de bases de datos computarizadas especialmente adaptadas a ese ámbito. Su objetivo es analizar, por ejemplo, las iniciativas de registro de patentes, estrategias de internacionalización de un país, las iniciativas en un sector, una tecnología o una empresa, con objeto de determinar o prever la orientación de la evolución tecnológica, o establecer la posición relativa de una empresa en el mercado, etcétera. Pero, además, su utilización se ha extendido a muchas actividades comerciales tácticas y estratégicas diferentes, a la investigación y a las actividades de formulación de políticas de nivel nacional, institucional o de las empresas" (Soonwoo Hong, 2008, p. 1).
} 
res sobresalientes y sus tendencias en el registro de patentes, y vi) un mapa de la situación geográfica de los inventores, para saber en dónde se está gestando el conocimiento (origen geográfico del invento), además de permitir "identificar cuáles son las empresas que están invirtiendo en ID” (OMPI, 2005) y de "contener información que no suele divulgarse en ningún otro tipo de documentos y abarcar prácticamente todos los campos de la tecnología" (OMPI, 2009).

El uso de las patentes ha evolucionado con el tiempo. Estudiosos de los procesos de innovación han tratado de dar explicación a las trayectorias económicas y tecnológicas de los países por medio de este tipo de indicadores. ${ }^{11} \mathrm{C}$. Gay et al. $(2005)^{12}$ presentan una nueva propuesta en el manejo de este indicador proxy de la actividad inventiva al analizar y considerar como agentes principales a los inventores y pensarlos como prolíficos y estratégicos en la producción del conocimiento tecnológico de las naciones. Investigaciones de la OMPI (2005) coinciden en que "el análisis de la información sobre patentes permite identificar a los inventores que son fundamentales para el futuro de las empresas. Identificar su perfil intelectual constituye una herramienta útil para la búsqueda o la retención de inventores con talento, demostrando que un pequeño número de inventores prolífcos es un verdadero motor de desarrollo tecnológico, mientras que la mayoría de los investigadores llega a patentar apenas una o dos innovaciones".

Freeman (1982) afirma que "aunque las patentes son un indicador de la actividad en investigación aplicada y en desarrollo experimental, éstas sólo mi-

11 Los que se consideran más relevantes: Schmookler (1962), "Fuentes económicas de la actividad inventiva"; Archibugi y Coco (2004), "A New Indicator of Technological Capabilities for Developed and Developing Countries (ArCo)"; Griliches, Z. (1990), "Patent Statistics as Economic Indicators: A Survey", C. Gay, W. Lathman y Le Bas (2005), "Collective Knowledge, Prolific Inventors and the Value of Inventions: An Empirical Study of French, German and British Owned U.S. Patents, 1975-1998"; Hu y Jaffe (2001), "Patent Citations and International Knowledge Flow: The Case of Korea and Taiwan”; Hall, Jaffe y Trajtenberg (2001), "The NBER Patent Citation Data File: Lessons, Insights and Methodological Tools".

${ }^{12}$ C. Gay et al. (2005, p. 16) analizan la existencia de inventores prolíficos en Francia, Alemania y Reino Unido durante 1975 y 1999. Estos autores analizan variables como el número y los nombres de inventores, su nacionalidad y el número de citas, y con dicha información realizan una estimación econométrica. Cabe destacar que a diferencia de su estudio, para el análisis, en este artículo, sólo se calcula la frecuencia del registro de patentes por inventor (no se realiza un modelo econométrico). Ellos verifican la existencia de una correlación alta y positiva entre la presencia de IP y el valor tecnológico de las invenciones patentadas, medida por el número de citas recibidas posteriormente por una patente. Concluyen que "en el contexto de la generación de conocimientos tecnológicos, el conocimiento integrador de sistemas (el inventor prolífico) pretende coordinar la competencia y capacidad de los miembros del equipo con el fin de aumentar el rendimiento de las empresas tecnológicas y su competitividad económica". 
den una parte del output. ${ }^{13}$ Algunos inventos no se patentan por distintas razones, entre otras: $i$ ) los inventores creen que carecen de aplicación industrial; ii) están protegidos por el secreto industrial y sus inventores creen que la seguridad es mayor sin protección de la patente; iii) los inventores piensan que el liderazgo científico y técnico es más importante que la protección que confiere la patente; iv) las peculiaridades de la legislación sobre patentes afectan a ciertas clases de inventos; $v$ ) por la demora, el coste o la dificultad que implica patentar, y vi) por los factores legales que afectan a las patentes, tales como la legislación antimonopolio. Sin embargo, puede replicarse que, a pesar de estas limitaciones, pueden utilizarse las estadísticas de patentes para medir una parte importante del output de investigación aplicada y desarrollo experimental, o de trabajo de inventiva".

Antes de mostrar la evidencia relacionada con los IP y las áreas tecnológicas de especialización que definen el patrón tecnológico de México y Corea durante 1978-2006, se describen brevemente los mecanismos de construcción, selección y manejo de la información de patentes utilizada para este estudio.

\section{Metodología: información de patentes}

El estudio se realiza a partir de una metodología cuantitativa, orientada a la:

a) Construcción de bases de datos de México y Corea, con información de registros de patentes otorgadas ${ }^{14}$ de 1978 a 2006 por la USPTO. ${ }^{15}$

b) Selección de los IP de acuerdo con la frecuencia de ocurrencia en patentes (o grado de participación: cinco patentes o más).

c) Identificación del campo tecnológico (área de especialización) de los IP en el que han registrado sus innovaciones.

${ }^{13} \mathrm{El}$ output es entendido como la cantidad producida de información que puede obtenerse mediante la consulta de los registros de patentes.

${ }^{14}$ El criterio de selección de las patentes de la USPTO que se utilizan, fue el de las patentes registradas entre 1978-2006 que tuvieran al menos un inventor mexicano (en el caso de patentes de México) y al menos un inventor coreano (en el caso de las patentes de Corea).

15 "El gran polo de atracción es la USPTO, adonde la mayoría de las transacciones relacionadas con la tecnología tienen lugar. Tres bloques económicos (Estados Unidos, Europa y Asia) son los más importantes en el mundo y representan más de 90\% del registro de patentes total registrado" (Aboites y Cimoli, 2002). La información contenida en los documentos de patente de USPTO: $i$ ) es actualizada regularmente; ii) el diseño y la forma en que son presentados los documentos es clara, uniforme y estructurada; iii) pueden obtenerse desde los nombres de los inventores y fechas de otorgamiento, hasta los resúmenes y diseños de los inventos, y iv) se pueden, por tanto, comparar datos con las mismas características para distintos países. 
Por la información contenida en las patentes ${ }^{16}$ éstas son un importante insumo para identificar a los IP y las áreas tecnológicas en las cuales se desempeñan. Las variables contenidas en sus registros permiten reconocer: $i$ ) el número de registro del invento, ii) el título de la patente, iii) el año de solicitud y otorgamiento, $i v)$ el nombre del inventor, su posición en la patente y nacionalidad, $v$ ) nombre del titular y nacionalidad, vi) clasificación y subclasificación tecnológica del invento, vii) y el número de citas que hacen referencia a la innovación. ${ }^{17}$

\section{Clasificación de patentes por campo tecnológico}

Para la identificación de los campos tecnológicos en los que están clasificadas las patentes, se retoma la metodología de Hall, Jaffe y Trajtenberg (2001), quienes de acuerdo con la clasificación tecnológica de Estados Unidos, categorizan en seis campos principales las invenciones, a saber: $i$ ) cómputo y comunicaciones, ii) eléctrica-electrónica, iii) medicina y farmacia, iv) química, v) mecánica, y vi) otros (véase anexos 1a y 1b).

\section{Criterio de selección de los IP}

La principal condición por la que se elige emplear a las patentes como indicador proxy de la actividad inventiva de los IP es porque se pueden obtener los nombres de los inventores ${ }^{18}$ y las áreas tecnológicas en las que se especializan.

En el estudio de C. Gay et al. (2005), la característica para determinar el grado de participación de un inventor y caracterizarlo como prolífico es el número de veces que su nombre aparece registrado en la patente (un rango de 10 patentes o más). La interrogante que surge es: ¿cuál es el número de patentes en las que han participado los inventores más dinámicos de México y Corea que permita identificarlos como inventores clave? Éste es precisamente parte del trabajo exploratorio que se realiza en esta investigación.

${ }^{16}$ Aunque se sabe, que existen otras fuentes donde el conocimiento puede ser acumulado: "capital humano" - conocimiento tácito-, revistas, artículos científicos, libros, etcétera.

${ }^{17}$ Para este estudio en particular no se utiliza la información relacionada con el año de solicitud, los titulares y las citas (backward y forward) asociadas con las patentes.

18 "El número de inventores que figuran en el documento de patente proporciona información útil sobre el tamaño de la actividad inventiva del equipo y por tanto, de la dimensión colectiva de la creación de conocimiento. Utilizamos este indicador de la misma manera que se utiliza en bibliometría: allí, el número de autores da un indicador de creación colectiva en las publicaciones científicas" (C. Gay et al., 2005). 
La evidencia muestra que la frecuencia en el registro de patentes para el caso de México hace indispensable abrir el rango (cinco patentes o más), debido a que los IP donde al menos un inventor es mexicano registran una baja participación en actividades inventivas y no hubiera sido posible elegir un número considerable de ellos para ser analizados. Así, la característica principal está en función del número de patentes por inventor (sin importar la posición que ocupe el inventor en la patente). ${ }^{19}$

La información recopilada por medio de la USPTO (1978-2006) fue de 1908 patentes con al menos un inventor mexicano y 45022 patentes con al menos un inventor coreano (véase cuadro 1 y anexo 2 ).

CUADRO 1. México y Corea: principales diferencias entre patentes otorgadas, total de inventores e inventores prolíficos, 1978-2006*20

\begin{tabular}{|l|c|c|}
\hline \multicolumn{1}{|c|}{ Variables } & México & Corea \\
\hline Total de patentes & 1908 & 45022 \\
\hline Total de inventores* & 3747 & 66271 \\
\hline Inventores prolíficos & $128=3.4 \%$ & $5472=8.26 \%$ \\
\hline Rango de patentes & 5 o más (22) & 5 o más (146) \\
\hline
\end{tabular}

* El total de inventores representa no sólo a los que se encuentran registrados como "primer inventor", sino al total de éstos que participan en la patente, sin importar su posición.

Fuente: Elaboración propia a partir de USPTO (2008).

El cuadro 1 muestra el total de patentes otorgadas, el número total de inventores y el número de IP. Para la economía mexicana son 128 los IP (con cinco patentes o más), representando $3.4 \%$ del total de inventores; en comparación, el número de los de Corea arroja un resultado significativo de 5472 IP (con cinco patentes o más) siendo $8.26 \%$ del total de inventores coreanos. En el caso de las patentes con participación de al menos un inventor mexicano, el más prolífico registró 22 patentes (Muchowski) y en el caso de Corea 146 fueron las patentes

\footnotetext{
${ }^{19}$ El estudio de C. Gay et al. (2005) únicamente se basa en el análisis del primer inventor. A diferencia de ello, en este estudio se analiza el total de inventores que participan en la patente, debido a que no se tiene certeza de que la posición del inventor (en este caso el primero, como lo hacen los autores) sea determinante para generalizar su activa participación como creador y gestor de nuevas ideas.

${ }^{20}$ Hay que considerar que una patente puede abarcar más de un inventor, por lo que el total de inventores puede ser superior al total de patentes.
} 
registradas por el inventor más prolífico (Hee Bok Kang). En ese sentido, los IP coreanos confirman la primera característica que plantea C. Gay et al. (2005, p. 16) en relación con que dichos inventores son promotores activos de la producción de nuevas ideas y ello se encuentra reflejado en una apreciable y constante participación en el registro de patentes.

La evidencia que se presenta a continuación se refiere al conjunto de inventores más prolíficos durante 1978-2006 de México y Corea, los cuales fueron seleccionados con los criterios antes mencionados.

\section{LOS INVENTORES PROLÍFICOS DE MÉXICO Y COREA, 1978-2006}

La baja producción de conocimiento de México registrada en patentes (1908) en comparación con el intenso flujo de Corea (45022) en las últimas décadas, puede asociarse con la baja participación de agentes innovadores en actividades de ID. La presencia de 128 IP en patentes mexicanas respecto a 5472 de la economía coreana podría sugerir una expresión de la gestión y promoción de las capacidades tecnológicas (aprendizaje colaborativo) en esta última economía, donde la presencia de capital intelectual especializado ha resultado en un aumento del esfuerzo tecnológico nacional.

Cabe subrayar que sólo 20 IP (15.62\% de los 128 inventores más dinámicos), con 283 patentes ( $14.78 \%$ del total), muestran un patrón de registro de patentes similar (10 patentes o más) al de países industrializados como Alemania, Francia y Reino Unido, ${ }^{21}$ lo que significa que en cerca de 30 años un grupo reducido de IP ha alcanzado un desempeño en la producción de nuevo conocimiento tecnológico (en grupos de investigación con al menos un inventor mexicano) semejante al de economías industrializadas.

Los nombres que se presentan en el cuadro 2 corresponden a esos primeros 20 IP. Esta lista es encabezada por el inventor Muchowski, quien registró 22 patentes durante un periodo de 10 años (1978-1992), que representan $64.71 \%$ del total de las patentes de Syntex (34), que es la empresa norteamericana con la cual se vinculó para realizar actividades de investigación tecnológica registrada en USPTO. Básicamente, sus patentes están asociadas con áreas tecnológicas como medicina y farmacia en 15 patentes $(68 \%)$ y química en 7 patentes $(32 \%)$. Desta-

\footnotetext{
${ }^{21}$ Las tendencias en el registro de patentes de los inventores prolificos en los tres países industrializados son a partir de un número de patentes igual a: Alemania (169852), Francia (65024) y Reino Unido (65064), durante un periodo que abarca de 1975 a 1999.
} 
CUADRO 2. México: inventores prolíficos IP con más patentes

(10 o más), 1978-2006

\begin{tabular}{|c|c|c|}
\hline Núm. & Nombre del inventor & Núm. patentes \\
\hline 1 & Muchowski, Joseph M. & 22 \\
\hline 2 & Lizardi, Paul M. & 21 \\
\hline 3 & Lazcano Navarro, Arturo & 20 \\
\hline 4 & Boss, Roland & 17 \\
\hline 5 & Viramontes Brown, Ricardo & 16 \\
\hline 6 & Cárdenas Franco, Luis & 15 \\
\hline 7 & Arias Álvarez, José A. & 14 \\
\hline 8 & Hernández, Néstor & 14 \\
\hline 9 & Rubio, Manuel J. & 14 \\
\hline 10 & Becerra Novoa, Jorge Octavio & 13 \\
\hline 11 & Kramer, Fred Russell & 13 \\
\hline 12 & Martínez Vera, Enrique R. & 13 \\
\hline 13 & Domenge, Alberto & 12 \\
\hline 14 & Greenhouse, Robert J. & 12 \\
\hline 15 & Vargas Gutiérrez, Gregorio & 12 \\
\hline 16 & Villavicencio, Eduardo J. & 12 \\
\hline 17 & Lin, Yingjie & 11 \\
\hline 18 & MacKay, Patrick W. & 11 \\
\hline 19 & Carrillo, Conrado & 10 \\
\hline 20 & Villarreal Treviño, Juan Antonio & 10 \\
\hline
\end{tabular}

Fuente: Elaboración propia a partir de USPTO (2008).

can dos aspectos: i) se identifica como el inventor más prolífico de las patentes mexicanas en USPTO, pero ii) por los menos en las patentes analizadas en este trabajo, es evidente que su productividad quedó estancada hace 14 años.

Algunas de las interrogantes que no pueden esclarecerse exclusivamente por medio de las patentes y que se espera responder en futuras investigaciones, son: ¿por qué México no se ha beneficiado de los flujos de conocimiento, dada la apertura económica internacional que tiene en la actualidad? ¿Por qué en México no se registra una tasa de registro de patentes notoria, si en la actualidad se reconoce que el conocimiento es un recurso clave que impulsa el proceso de innovación y representa una estrategia para que las empresas sean más competitivas, y tomando en cuenta que esos registros representan un significativo acervo de co- 
nocimientos? La brecha entre México y Corea se hace notoria al revisar el conjunto de inventores especializados de esta última economía.

En el caso de los IP coreanos, los primeros 23 nombres de la lista (cuadro 3) mostraron un patrón de registro de patentes más trascendente (61 o más). Estos IP son más productivos en conocimiento; en comparación con los IP en patentes mexicanas representan $8.26 \%$ del total de inventores registrados (66271) de Corea y acumulan un total de 1884 patentes (4.19\% del total de patentes otorgadas).

El inventor Hee Bok Kang encabeza la lista con 146 patentes durante 13 años (1994-2006). Sus principales características son: $i$ ) es un inventor que se ha vinculado a 103 patentes como inventor-empresa; ii) en 43 patentes participa con más de un inventor (equipo de investigación); iii) la única empresa con la que este inventor colabora es Hynix Semiconductor (coreana), que representa 3.2\% del registro de patentes total de Corea, y iv) participa con esa empresa en $100(7 \%)$ de las 1457 patentes que registra Hynix.

La evidencia permite reflexionar acerca de la importancia que tiene: $i$ ) el financiamiento de actividades relacionadas con ID que promuevan al perfeccionamiento de las capacidades de los inventores y demás agentes económicos que participan dentro del proceso de innovación, como estrategia para que las economías se tornen más competitivas, y ii) incrementar la promoción de la formación de grupos de investigación, identificando a los inventores clave como gestores en la búsqueda de novedosas formas de resolución de problemas y, por tanto, de la identificación de nuevas tecnologías.

En suma, el número de inventores representa el conjunto de agentes especializados y calificados capaces de producir un gran acervo de conocimiento explícito que resulte en la búsqueda de soluciones a problemas técnicos en una economía específica. El caso de Corea sugiere que es una economía donde las instituciones y los hacedores de política se han preocupado por financiar actividades de ID concernientes a la promoción, formación de grupos de investigación y fortalecimiento de las capacidades centrales de los inventores clave como gestores del conocimiento, además de proveer la infraestructura adecuada para reconocer oportunidades tecnológicas novedosas.

El Banco Mundial (2006) plantea que los factores asociados al crecimiento de Corea pueden atribuirse a:

la acumulación de conocimientos, en lugar de acumulación de factores tradicionales de producción de capital y mano de obra. En Corea se han hecho notables esfuerzos en inversiones en educación y formación de capital humano, fomento 
de la innovación a través de ID, el desarrollo de una infraestructura moderna y accesible a la información, junto con una economía estable y un adecuado régimen institucional que ha permitido que los conocimientos relacionados con las inversiones puedan prosperar. Así, Corea ha hecho su transición a una economía del conocimiento, es decir, una economía que utiliza el conocimiento como el motor clave para su crecimiento.

Asimismo, el análisis de la evolución del registro de patentes de los países seleccionados permite corroborar (gráfica 1) que el flujo de patentes de Corea en relación con el total de IP es notorio y refleja un rezago en el caso de México.

CUADRO 3. Corea: inventores prolíficos con más patentes (61 patentes o más), 1978-2006

\begin{tabular}{|c|c|c|}
\hline Núm. & Nombre del inventor & Núm. patentes \\
\hline 1 & Kang, Hee Bok & 146 \\
\hline 2 & Ko, Jung Wan & 137 \\
\hline 3 & Lee, Chul Woo & 113 \\
\hline 4 & Jung, Jae Chang & 106 \\
\hline 5 & Kim, Dong Gvu & 105 \\
\hline 6 & Park, In Sik & 93 \\
\hline 7 & Baik, Ki Ho & 89 \\
\hline 8 & Chung, Chong Sam & 82 \\
\hline 9 & Kim, J ae Kap & 81 \\
\hline 10 & Lee, Geun Su & 74 \\
\hline 11 & Yoo, Jang Hoon & 74 \\
\hline 12 & Lee, Jae Jin & 70 \\
\hline 13 & Jun, Young Kwon & 69 \\
\hline 14 & Jung, Min Ho & 69 \\
\hline 15 & Cho, Kun Ho & 66 \\
\hline 16 & Lee, Jin Soo & 66 \\
\hline 17 & Park, Jae Yong & 66 \\
\hline 18 & Ahn, Jae Min & 64 \\
\hline 19 & Lee, Kyung Geun & 64 \\
\hline 20 & Choi, Sang Jun & 63 \\
\hline 21 & Kim, Ki Nam & 63 \\
\hline 22 & Park, Woon Yong & 63 \\
\hline 23 & Hwang, Seong Taek & 61 \\
\hline
\end{tabular}

Fuente: Elaboración propia a partir de USPTO (2008). 
La evidencia refuerza el planteamiento respecto al gran dinamismo que logró Corea a partir de mediados de los ochenta, en cuanto a su crecimiento y desempeño tecnológicos, después de las condiciones similares e incluso inferiores que guardaba con México.

Las tendencias registradas en el periodo 1978-2006 resultan apreciables: los flujos de patentes de México crecen a una tasa promedio de $4.15 \%$ anual, en tanto que la producción de conocimiento de Corea, medida en patentes, crece a un promedio anual de $31.20 \%$. "El sistema de patentes de Corea está caracterizado por un conjunto de incentivos que apoyan la difusión de la innovación y la protección de capacidades tecnológicas alcanzadas durante el periodo de industrialización" (Aboites y Cimoli, 2002), lo que no se verifica en el caso mexicano.

Se esperaría que la relación entre un mayor número de patentes y una intensa participación de inventores fuera positiva (como lo plantean C. Gay et al., 2005), sin embargo, en el caso de México, esa tendencia parece no comprobarse. La participación de los inventores en relación con el número de patentes parece divergir en el tiempo. El número de los que participan en actividades de ID tan sólo se multiplica por cinco durante todo el periodo (de cinco a 26 inventores) y la tasa de crecimiento fue de $6.06 \%$, promedio anual. En Corea existe una participación más activa de los IP, los que además abren una brecha significativa de

GRÁFICA 1. México y Corea: número de patentes e inventores prolíficos, 1978-2006 (SEMILOG)

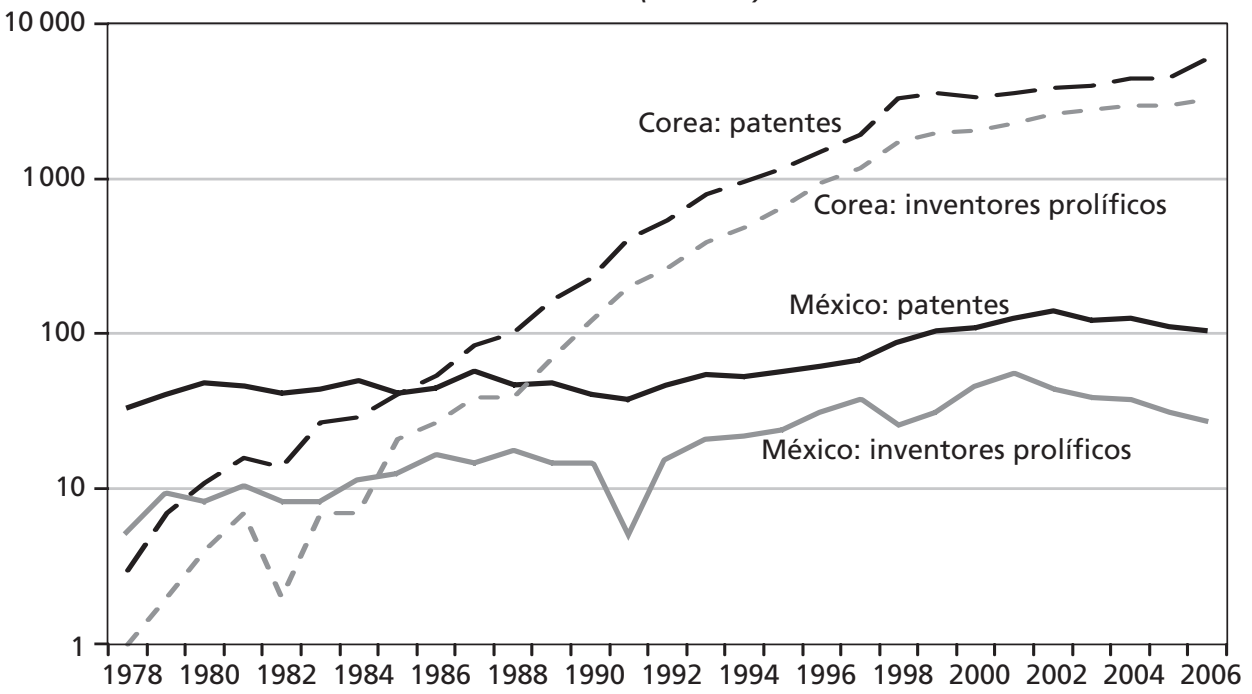

Fuente: Elaboración propia a partir de USPTO (2008). 
participación en relación con los IP de México. En Corea, la tasa de crecimiento promedio de participación de los IP durante el periodo fue de $33.53 \%$, es decir, se pasa de un IP en 1978 a 3282 (2006) inventores notorios en la producción de conocimiento tecnológico (anexo 2).

En el flujo de registro de patentes, como en el número de inventores, existe una eminente brecha entre los dos países: $i$ ) brecha en la producción de nuevo conocimiento registrado en patentes, y ii) brecha en el número de IP que participan como promotores activos de la innovación, la cual a partir de mediados de los ochenta parece constante.

Las áreas tecnológicas en las cuales se clasifican las patentes, y en las que se especializan los IP, también muestran una actividad interesante.

\section{México y Corea: evolución del patentamiento de los IP por campo tecnológico}

El cuadro 4 muestra la distribución absoluta y porcentual del total de patentes clasificadas según campo tecnológico en el que participan los IP de México y Corea. La especialización tecnológica de los IP de México se encuentra asociada con el paradigma tecnológico anterior (modelo de industrialización por sustitución de importaciones, ISI). Dos terceras partes (62.5\%) de las patentes están concentradas en campos tecnológicos tradicionales, principalmente en el sector mecánica $(35.9 \%)$. La otra tercera parte del total de patentes está fuertemente relacionada con el campo tecnológico de medicina y farmacia $(24 \%)$ en lo que respecta a las áreas de tecnologías modernas (anexo 3).

La división tecnológica de las patentes de los IP del país asiático en comparación con la de México es muy distinta y está dentro de los campos de especialización moderna. En primer lugar, destacan las innovaciones catalogadas dentro de la eléctrica-electrónica (36.8\%), seguidas de aquellas en cómputo y comunicaciones $(26.1 \%)$, lo que indica que los IP del país asiático se desarrollan en áreas relacionadas con el paradigma actual de las tecnologías de la información y las telecomunicaciones (TIC), es decir, sectores más competitivos, bajo un intercambio de conocimiento más especializado entre los agentes innovadores. En Corea, dos terceras partes de las patentes de los IP se concentran en el sector moderno $(66.8 \%)$, es decir, en tecnologías que representan mayor valor y complejidad, lo que puede incorporar a los IP de ese país a empresas con mayor dinamismo a escala mundial, con mayores oportunidades de desarrollo de su capacidad de aprendizaje. Tal parece que ello se caracteriza por la activa participación en investiga- 
CUADRO 4. México y Corea: patentes otorgadas por la USPTO a inventores prolíficos por campo tecnológico, 1978-2006

\begin{tabular}{|l|r|r|r|r|}
\hline \multirow{2}{*}{ Campos tecnológicos } & \multicolumn{2}{c|}{ México } & \multicolumn{2}{c|}{ Corea } \\
\cline { 2 - 5 } & Núm. patentes & Porcentaje & Núm. patentes & Porcentaje \\
\hline Tradicionales & 158 & 16.4 & 3450 & 6.3 \\
\hline Otros & 345 & 35.9 & 5345 & 9.8 \\
\hline Mecánica & 98 & 10.2 & 9347 & 17.1 \\
\hline Química & 601 & 62.5 & 18142 & 33.2 \\
\hline Subtotal & 231 & 24.0 & 2145 & 3.9 \\
\hline Modernos & 85 & 8.8 & 20131 & 36.8 \\
\hline Medicina y farmacia & 44 & 4.6 & 14301 & 26.1 \\
\hline Eléctrica-electrónica & 360 & 37.5 & 36577 & 66.8 \\
\hline Computo y comunicaciones & 961 & 100 & 54719 & 100 \\
\hline Subtotal & 96 & & \\
\hline Total* &
\end{tabular}

* Número de patentes del grupo de IP con cinco o más patentes.

Fuente: Elaboración propia a partir de USPTO (2008).

ción en áreas que aportan más a los procesos de innovación, de acuerdo con los requerimientos globales (anexo 4).

En cuanto a la participación de los IP por sector tecnológico, destacan dos aspectos: $i$ ) tanto el número de IP con especialización tecnológica en el sector moderno como en el tradicional es significativamente mayor en el caso del país asiático; ii) en relación con el número absoluto de IP, es visible que la mayoría de los agentes innovadores (398 inventores del total), es decir, 60.9\% reafirman la tendencia del registro de patentes con su participación en el sector tecnológico tradicional. Caso contrario el de Corea, que de forma semejante a la del registro de sus innovaciones en áreas tecnológicas modernas, agrupa a 63.9\% de los IP por sector, es decir, a 19497 inventores del total (30526) (gráfica 2).

Otra tendencia importante es la del crecimiento promedio de IP con cinco patentes o más por sector tecnológico (moderno y tradicional), mientras que el crecimiento promedio de participación de inventores en patentes mexicanas representa $7.46 \%$, es decir, que se pasa de cuatro inventores en 1978 a 30 en 2006, lo que alude a grupos de investigación pequeños y a una baja promoción y creación del entorno propicio para la generación y difusión del conocimiento, y en alguna medida a la escasa creación de incentivos por parte de las instituciones encarga- 
GRÁfICA 2. México y Corea: inventores prolíficos por sector tecnológico,

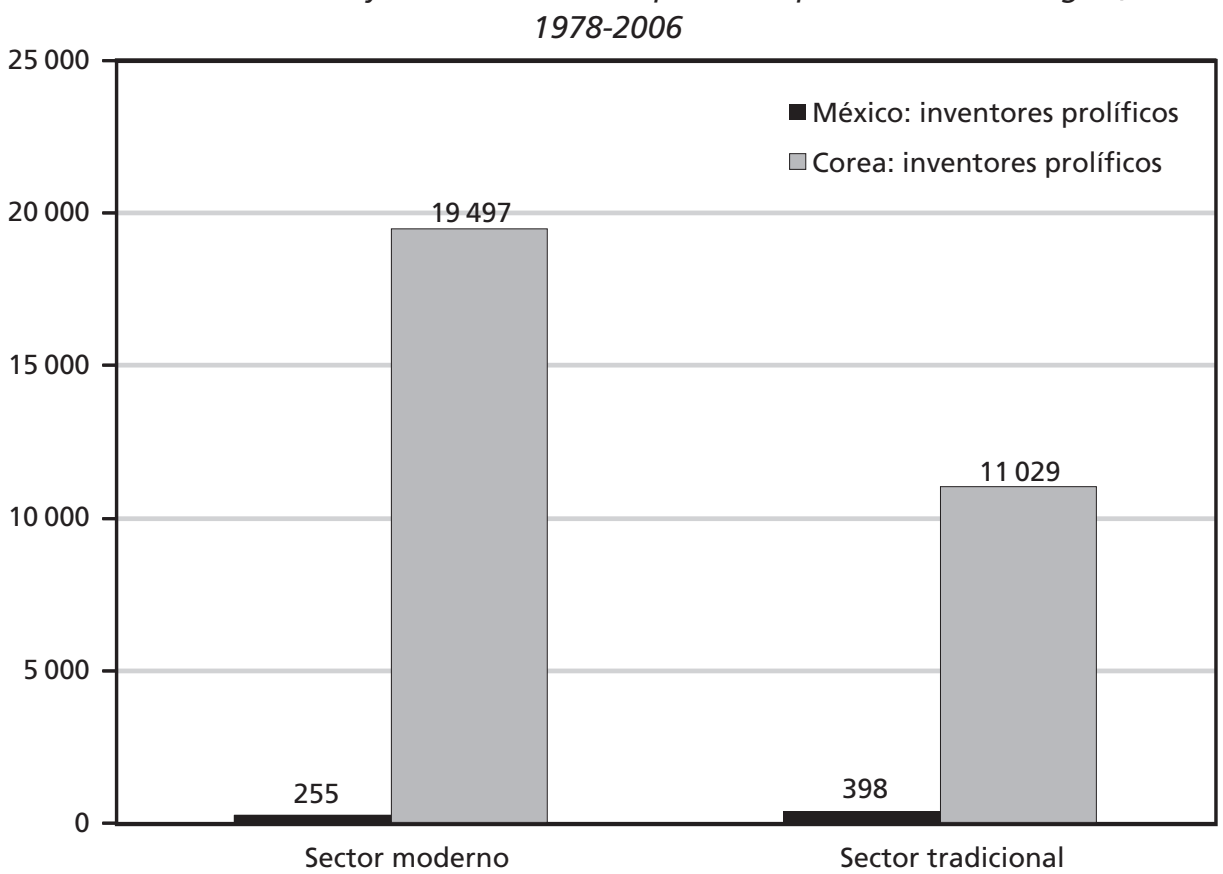

Fuente: Elaboración propia a partir de USPTO (2008).

das de promover actividades relacionadas con ID. Sin embargo, en Corea, la actividad de los IP va en aumento. A finales del periodo, el total de las patentes registradas cuenta con una participación de 3599 IP (11.8\% del total de IP por sectores tecnológicos), lo que significó un crecimiento promedio de $33.97 \%$ (anexo 5).

El que los IP coreanos estén insertados en sectores modernos, especializándose en nuevas áreas de registro de patentes, representa en algún sentido un proceso de adaptación de esos inventores a la exploración del espectro de los requerimientos del mercado actual, desarrollando la capacidad de evolucionar a la par de las exigencias de la competencia. Se genera una cadena de valor, en el sentido de que, a mayor especialización, existe mayor probabilidad de diversificar sus productos e insertarse en nuevos mercados.

El comportamiento de los flujos de patentes y la participación de los IP como agentes innovadores clave en el proceso de innovación reflejan un rezago tecnológico de la economía mexicana, generado por la baja producción de nuevo conocimiento e incorporación de éste en el desarrollo de nuevas tecnologías. Países como México, que adoptaron un modelo de sustitución de importaciones, 
tendieron a importar innovaciones reduciendo su capacidad tecnológica local. La apertura económica no ha sido condición suficiente para tener un alto rendimiento tecnológico, debido a que si en el ámbito productivo "interno" no se logra transferir y adaptar conocimientos y capacidades técnicas para su modernización, no se logrará el objetivo de una eficiente promoción de la imitación, los procesos de aprendizaje y la difusión tecnológica al interior de la economía.

\section{REFLEXIONES FINALES}

El nuevo conocimiento producido por los inventores prolíficos se torna explícito al registrarse en las patentes. Éstas representan acervos de información estratégicos e importantes y conocimiento tecnológico para las economías y los agentes que en ellas participan en el proceso de innovación.

La patente, al ser un indicador proxy de la actividad inventiva, y por la información que contiene, permite la identificación de los inventores más creativos y dinámicos cuyo esfuerzo se concentra en la novedad. Sin embargo, aunque se reconoce la importancia de acumular conocimiento como factor que estimula el crecimiento y el progreso tecnológico, en países en desarrollo como México no se ha establecido un régimen orientado a facultar las capacidades de aprendizaje, imitación y adaptación del conocimiento existente, para producir nuevas tecnologías. Además, la baja participación de IP en esta economía sugiere: $i$ ) una disminución de la creación de redes con otros inventores y de la transferencia de conocimiento tácito-explícito a otros agentes, y ii) pérdida de oportunidades de "aprender" otras técnicas para hacer las cosas, formas de pensar, plantear y resolver problemas y el acceso a otra infraestructura. La creación y aplicación de leyes que impulsen el factor tecnológico en diversos ámbitos de la economía es un vacío que debe llenarse.

La participación activa que han tenido los IP en el caso de Corea sugiere que el gobierno, las instituciones y los mismos inventores han reconocido el alto valor que representa la producción de nuevo conocimiento registrado en títulos de propiedad y la necesidad que existe de contribuir a los procesos de innovación y de cambio tecnológico para competir en la economía mundial. El comportamiento de los flujos de patentes en los que participan los inventores de Corea presentó tendencias notorias, con una intensa actividad en rubros directamente asociados a la emergencia de la producción de nuevo conocimiento con el paradigma actual de la información y las comunicaciones. En el caso de México, los IP mexicanos se especializan aún en áreas tecnológicas tradicionales (mecánica y química). Sin 
embargo, se plantea que las políticas tecnológicas no deberían concretar planes y programas sin un amplio reconocimiento de las capacidades centrales y de los sectores estratégicos de la economía que permitieran reinterpretar el entramado institucional para adaptarse a los requerimientos de la industria — ambientes cooperativos con un sentido colectivo - como los grupos de investigación donde participan los IP, debido a las transformaciones continuas que implica el contexto global.

Un factor clave estaría en tomar en cuenta la vinculación entre las políticas tecnológicas y de desarrollo, en el sentido de que la promoción de la innovación, y todo lo que ésta implica para concretarse, requiere considerar los intereses de todos los agentes que componen la sociedad, háblese de productores, consumidores, empresarios, investigadores, inventores y el conjunto de actores que componen una economía, es decir, políticas que identifiquen necesidades locales. En el caso de México, identificar las capacidades centrales de los IP para canalizarlos a sectores estratégicos de la industria donde puedan transferir de forma eficiente su background de conocimiento.

Debe tomarse en cuenta que el incremento en las rentas derivadas del esfuerzo innovador no depende tan sólo de alcanzar cierta especialización y grado de competencia en el mercado. Los hacedores de política también son responsables de la captación de beneficios si encauzan y promueven estrategias que vinculen a los actores de forma eficiente, objetiva y oportuna.

El interés por generar un acervo de conocimiento y fortalecer las capacidades centrales de los IP de las economías estudiadas (en especial de la mexicana), por ejemplo, mediante un mayor grado de educación y especialización, también tiene la finalidad de cerrar la brecha tecnológica existente entre los países desarrollados y en desarrollo, como en el caso de México y Corea, que hace cerca de 30 años presentaban condiciones similares en la producción de conocimiento y en la participación de los inventores en el proceso de innovación, que hoy en día diverge en los dos países. 


\section{ANEXOS}

ANEXO 1A. Clasificación de patentes por campo y subcampo tecnológico, según Hall, Jaffe y Trajtenberg

\begin{tabular}{|c|c|c|c|}
\hline \multicolumn{2}{|c|}{ Campo tecnológico } & Subcampo tecnológico & Número de clasificación tecnológica USPTO \\
\hline \multicolumn{4}{|c|}{ Sector moderno } \\
\hline \multirow{4}{*}{1} & \multirow{4}{*}{$\begin{array}{l}\text { Cómputo y } \\
\text { comunicaciones }\end{array}$} & Comunicaciones & $\begin{array}{l}178,333,340,342,343,358,367,370,375 \\
379,385,455,719\end{array}$ \\
\hline & & Cómputo: hardware y software & $\begin{array}{l}341,380,382,395,700,701,702,703,704, \\
705,706,707,708,709,710,712,713,714, \\
726,717\end{array}$ \\
\hline & & Cómputo: periféricos & 345,347 \\
\hline & & $\begin{array}{l}\text { Cómputo: almacenamiento } \\
\text { de información }\end{array}$ & $360,365,369,711,716,718,725$ \\
\hline \multirow{7}{*}{2} & \multirow{7}{*}{$\begin{array}{l}\text { Eléctrica y } \\
\text { electrónica }\end{array}$} & Aparatos eléctricos & $\begin{array}{l}174,200,327,329,330,331,332,334,335 \\
336,337,338,392,439\end{array}$ \\
\hline & & Iluminación eléctrica & $313,314,315,362,372,445$ \\
\hline & & $\begin{array}{l}\text { Instrumentos de medida observación } \\
\text { y experimentación }\end{array}$ & $73,324,356,374$ \\
\hline & & Rayos $\mathrm{X}$ y nucleares & $250,376,378$ \\
\hline & & Sistemas de energía & $\begin{array}{l}60,136,290,310,318,320,322,323,361, \\
363,388,429\end{array}$ \\
\hline & & Semiconductores & $257,326,438,505$ \\
\hline & & Miscelánea - Eléc. & $191,218,219,307,346,348,377,381,386$ \\
\hline \multirow{4}{*}{3} & \multirow{4}{*}{$\begin{array}{l}\text { Medicina y } \\
\text { farmacia }\end{array}$} & Medicamentos & 424,514 \\
\hline & & Instrumentos médicos y quirúrgicos & $128,600,601,602,604,606,607$ \\
\hline & & Biotecnología & 435,800 \\
\hline & & Miscelánea farmacéutica & $351,433,623$ \\
\hline
\end{tabular}

Fuente: Hall, Jaffe y Trajtenberg (2001). 
112 ECONOMÍA: TEORÍA Y PRÁCTICA • Nueva Época, número 29, julio-diciembre 2008

ANEXO 1B. Clasificación de patentes por campo y subcampo tecnológico, según Hall, Jaffe-Trajtenberg

\begin{tabular}{|c|c|c|c|}
\hline \multicolumn{2}{|c|}{ Campo tecnológico } & Subcampo tecnológico & Número de clasificación tecnológica USPTO \\
\hline \multicolumn{4}{|c|}{ Sector tradicional } \\
\hline \multirow{6}{*}{4} & \multirow{6}{*}{ Química } & Agricultura, alimentos, textiles & $8,19,71,127,442,504$ \\
\hline & & Recubrimientos & $106,118,401,427$ \\
\hline & & Gas & $48,55,95,96$ \\
\hline & & Componentes orgánicos & $\begin{array}{l}534,536,540,544,546,548,549,552,554,556, \\
558,560,562,564,568,570\end{array}$ \\
\hline & & Resinas & $520,521,522,523,524,525,526,527,528,530$ \\
\hline & & Miscelánea química & $\begin{array}{l}23,34,44,102,117,149,156,159,162,196,201, \\
202,203,204,205,208,210,216,222,252,260, \\
261,349,366,416,422,423,430,436,494,501, \\
502,510,512,516,518,585,588\end{array}$ \\
\hline \multirow{6}{*}{5} & \multirow{6}{*}{ Mecánica } & $\begin{array}{l}\text { Procesamiento de materiales } \\
\text { y manufactura }\end{array}$ & $\begin{array}{l}65,82,83,125,141,142,144,173,209,221,225, \\
226,234,241,242,264,271,407,408,409,414, \\
425,451,493\end{array}$ \\
\hline & & Metalurgia & $\begin{array}{l}29,72,75,76,140,147,148,163,164,228,266, \\
270,413,419,420\end{array}$ \\
\hline & & Motores y partes & $\begin{array}{l}91,92,123,185,188,192,251,303,415,417,418, \\
464,474,475,476,477\end{array}$ \\
\hline & & Óptica & $352,353,355,359,396,399,720$ \\
\hline & & Transporte & $\begin{array}{l}104,105,114,152,180,187,213,238,244,246, \\
258,280,293,295,296,298,301,305,410,440\end{array}$ \\
\hline & & Miscelánea-mecánica & $\begin{array}{l}7,16,42,49,51,74,81,86,89,100,124,157,184, \\
193,194,198,212,227,235,239,254,267,291, \\
294,384,400,402,406,411,453,454,470,482, \\
483,492,508\end{array}$ \\
\hline \multirow{9}{*}{6} & \multirow{9}{*}{ Otros } & Agricultura, ganadería y alimentos & $43,47,56,99,111,119,131,426,449,452,460$ \\
\hline & & Equipo de entretenimiento & $273,446,463,472,473$ \\
\hline & & Vestido y textiles & $\begin{array}{l}2,12,24,26,28,36,38,57,66,68,69,79,87,112, \\
139,223,450\end{array}$ \\
\hline & & Excavación & $37,166,171,172,175,299,405,507$ \\
\hline & & Muebles & $4,5,30,70,132,182,211,256,297,312$ \\
\hline & & Calefacción & $110,122,126,165,237,373,431,432$ \\
\hline & & Tuberías y ensamblaje & $138,277,285,403$ \\
\hline & & Recipientes & $53,206,215,217,220,224,229,232,383$ \\
\hline & & Miscelánea - otros & $\begin{array}{l}1,14,15,27,33,40,52,54,59,62,63,84,101,108, \\
109,116,134,135,137,150,160,168,169,177, \\
181,186,190,199,231,236,245,248,249,269, \\
276,278,279,281,283,289,292,300,368,404, \\
412,428,434,441,462,503\end{array}$ \\
\hline
\end{tabular}

Fuente: Hall, Jaffe y Trajtenberg (2001). 
ANEXO 2. México y Corea: patentes totales e inventores prolíficos, 1978-2006*

\begin{tabular}{|c|c|c|c|c|}
\hline \multirow[b]{2}{*}{ Año } & \multicolumn{2}{|c|}{ México } & \multicolumn{2}{|c|}{ Corea } \\
\hline & Patentes & $\begin{array}{l}\text { Inventores } \\
\text { prolíficos }\end{array}$ & Patentes & $\begin{array}{c}\text { Inventores } \\
\text { prolíficos }\end{array}$ \\
\hline 1978 & 32 & 5 & 3 & 1 \\
\hline 1979 & 39 & 9 & 7 & 2 \\
\hline 1980 & 46 & 8 & 11 & 4 \\
\hline 1981 & 44 & 10 & 16 & 7 \\
\hline 1982 & 40 & 8 & 14 & 2 \\
\hline 1983 & 42 & 8 & 27 & 7 \\
\hline 1984 & 48 & 11 & 29 & 7 \\
\hline 1985 & 40 & 12 & 41 & 21 \\
\hline 1986 & 43 & 16 & 54 & 27 \\
\hline 1987 & 55 & 14 & 85 & 39 \\
\hline 1988 & 45 & 17 & 102 & 39 \\
\hline 1989 & 46 & 14 & 165 & 70 \\
\hline 1990 & 39 & 14 & 230 & 122 \\
\hline 1991 & 36 & 5 & 412 & 201 \\
\hline 1992 & 45 & 15 & 549 & 268 \\
\hline 1993 & 52 & 20 & 802 & 393 \\
\hline 1994 & 51 & 21 & 967 & 491 \\
\hline 1995 & 55 & 23 & 1185 & 670 \\
\hline 1996 & 59 & 30 & 1525 & 945 \\
\hline 1997 & 65 & 36 & 1950 & 1190 \\
\hline 1998 & 85 & 25 & 3322 & 1747 \\
\hline 1999 & 100 & 30 & 3621 & 2000 \\
\hline 2000 & 104 & 44 & 3394 & 2075 \\
\hline 2001 & 120 & 53 & 3616 & 2309 \\
\hline 2002 & 134 & 42 & 3868 & 2626 \\
\hline 2003 & 116 & 37 & 4049 & 2790 \\
\hline 2004 & 120 & 36 & 4514 & 2992 \\
\hline 2005 & 107 & 30 & 4452 & 3003 \\
\hline 2006 & 100 & 26 & 6012 & 3282 \\
\hline Total & 1908 & 619 & 45022 & 27330 \\
\hline
\end{tabular}

* Las diferencias en los totales pueden no coincidir con el original (México 128 y Corea 5472), debido a que un mismo inventor puede participar en más de una patente, registrada en más de un año de otorgamiento.

Fuente: Elaboración propia a partir de USPTO (2008). 
114 ECONOMÍA: TEORÍA Y PRÁCTICA • Nueva Época, número 29, julio-diciembre 2008

ANEXO 3. México: patentes otorgadas en USPTO a inventores prolíficos por campo tecnológico, 1978-2006*

\begin{tabular}{|c|c|c|c|c|c|c|c|}
\hline \multirow{3}{*}{ Año } & \multicolumn{6}{|c|}{ México } & \multirow{3}{*}{ Total } \\
\hline & \multicolumn{3}{|c|}{ Moderno } & \multicolumn{3}{|c|}{ Tradicional } & \\
\hline & $\begin{array}{c}\text { Cómputo y } \\
\text { comunicaciones }\end{array}$ & $\begin{array}{l}\text { Eléctrica - } \\
\text { electrónica }\end{array}$ & $\begin{array}{c}\text { Medicina y } \\
\text { farmacia }\end{array}$ & Mecánica & Otros & Química & \\
\hline 1978 & 0 & 0 & 1 & 7 & 2 & 0 & 10 \\
\hline 1979 & 0 & 2 & 0 & 6 & 3 & 0 & 11 \\
\hline 1980 & 0 & 2 & 0 & 6 & 2 & 3 & 13 \\
\hline 1981 & 0 & 1 & 0 & 12 & 3 & 1 & 17 \\
\hline 1982 & 0 & 0 & 1 & 4 & 1 & 7 & 13 \\
\hline 1983 & 0 & 0 & 9 & 7 & 0 & 0 & 16 \\
\hline 1984 & 0 & 2 & 3 & 3 & 1 & 8 & 17 \\
\hline 1985 & 0 & 1 & 12 & 6 & 2 & 0 & 21 \\
\hline 1986 & 1 & 2 & 3 & 11 & 2 & 1 & 20 \\
\hline 1987 & 0 & 2 & 10 & 10 & 5 & 3 & 30 \\
\hline 1988 & 2 & 0 & 3 & 17 & 3 & 0 & 25 \\
\hline 1989 & 0 & 1 & 3 & 9 & 1 & 5 & 19 \\
\hline 1990 & 0 & 0 & 5 & 4 & 6 & 1 & 16 \\
\hline 1991 & 0 & 0 & 1 & 3 & 1 & 0 & 5 \\
\hline 1992 & 1 & 0 & 4 & 9 & 2 & 4 & 20 \\
\hline 1993 & 4 & 0 & 7 & 7 & 3 & 4 & 25 \\
\hline 1994 & 0 & 0 & 7 & 8 & 0 & 11 & 26 \\
\hline 1995 & 0 & 0 & 13 & 8 & 2 & 2 & 25 \\
\hline 1996 & 0 & 0 & 20 & 2 & 6 & 8 & 36 \\
\hline 1997 & 2 & 0 & 24 & 10 & 8 & 2 & 46 \\
\hline 1998 & 1 & 0 & 19 & 10 & 2 & 11 & 43 \\
\hline 1999 & 0 & 1 & 14 & 11 & 7 & 4 & 37 \\
\hline 2000 & 3 & 1 & 18 & 43 & 7 & 2 & 74 \\
\hline 2001 & 1 & 4 & 6 & 53 & 32 & 1 & 97 \\
\hline 2002 & 2 & 8 & 2 & 29 & 20 & 10 & 71 \\
\hline 2003 & 10 & 12 & 23 & 17 & 6 & 3 & 71 \\
\hline 2004 & 5 & 21 & 8 & 10 & 7 & 5 & 56 \\
\hline 2005 & 3 & 11 & 12 & 14 & 15 & 2 & 57 \\
\hline 2006 & 9 & 14 & 3 & 9 & 9 & 0 & 44 \\
\hline Total & 44 & 85 & 231 & 345 & 158 & 98 & 961 \\
\hline
\end{tabular}

* Las diferencias en los totales pueden no coincidir con el original, debido a que una misma patente puede clasificarse en más de un año y en más de un campo tecnológico.

Fuente: Elaboración propia a partir de USPTO (2008). 
ANEXO 4. Corea: patentes otorgadas en la USPTO a inventores prolíficos por campo tecnológico, 1978-2006*

\begin{tabular}{|c|c|c|c|c|c|c|c|}
\hline \multirow{3}{*}{ Año } & \multicolumn{6}{|c|}{ Corea } & \multirow{3}{*}{ Total } \\
\hline & \multicolumn{3}{|c|}{ Moderno } & \multicolumn{3}{|c|}{ Tradicional } & \\
\hline & $\begin{array}{c}\text { Cómputo y } \\
\text { comunicaciones }\end{array}$ & $\begin{array}{l}\text { Eléctrica - } \\
\text { electrónica }\end{array}$ & $\begin{array}{c}\text { Medicina y } \\
\text { farmacia }\end{array}$ & Mecánica & Otros & Química & \\
\hline 1978 & 0 & 0 & 1 & 0 & 0 & 0 & 1 \\
\hline 1979 & 0 & 0 & 0 & 0 & ] & 2 & 3 \\
\hline 1980 & 0 & 0 & 0 & 0 & 1 & 3 & 4 \\
\hline 1981 & 0 & 0 & 2 & 0 & 2 & 4 & 8 \\
\hline 1982 & 1 & 1 & 0 & 0 & 0 & 0 & 2 \\
\hline 1983 & 0 & 0 & 2 & 1 & 3 & 1 & 7 \\
\hline 1984 & 0 & 3 & 0 & 2 & 0 & 2 & 7 \\
\hline 1985 & 1 & 2 & 2 & 5 & 5 & 7 & 22 \\
\hline 1986 & 0 & 8 & 1 & 0 & 10 & 10 & 29 \\
\hline 1987 & 8 & 18 & 0 & 6 & 5 & 6 & 43 \\
\hline 1988 & 5 & 14 & 3 & 7 & 8 & 7 & 44 \\
\hline 1989 & 12 & 26 & 1 & 13 & 9 & 19 & 80 \\
\hline 1990 & 15 & 64 & 9 & 16 & 12 & 39 & 155 \\
\hline 1991 & 36 & 112 & 6 & 40 & 19 & 43 & 256 \\
\hline 1992 & 79 & 161 & 20 & 37 & 20 & 68 & 385 \\
\hline 1993 & 87 & 228 & 40 & 53 & 39 & 91 & 538 \\
\hline 1994 & 153 & 286 & 48 & 90 & 46 & 95 & 718 \\
\hline 1995 & 213 & 390 & 49 & 96 & 93 & 213 & 1054 \\
\hline 1996 & 377 & 474 & 80 & 181 & 128 & 278 & 1518 \\
\hline 1997 & 480 & 712 & 144 & 249 & 149 & 271 & 2005 \\
\hline 1998 & 929 & 1070 & 139 & 318 & 225 & 562 & 3243 \\
\hline 1999 & 1005 & 1259 & 172 & 451 & 255 & 598 & 3740 \\
\hline 2000 & 993 & 1312 & 181 & 354 & 182 & 739 & 3761 \\
\hline 2001 & 1130 & 1593 & 206 & 395 & 160 & 724 & 4208 \\
\hline 2002 & 1365 & 1946 & 169 & 462 & 332 & 939 & 5213 \\
\hline 2003 & 1414 & 2240 & 270 & 549 & 317 & 1057 & 5847 \\
\hline 2004 & 1596 & 2680 & 250 & 498 & 474 & 1191 & 6689 \\
\hline 2005 & 1678 & 2437 & 164 & 647 & 498 & 1106 & 6530 \\
\hline 2006 & 2724 & 3095 & 186 & 875 & 457 & 1272 & 8609 \\
\hline Total & 14301 & 20131 & 2145 & 5345 & 3450 & 9347 & 54719 \\
\hline
\end{tabular}

* Las diferencias en los totales pueden no coincidir con el original, debido a que una misma patente puede clasificarse en más de un año y en más de un campo tecnológico.

FUENTE: Elaboración propia a partir de USPTO (2008). 
ANEXO 5. México y Corea: inventores prolíficos por sector tecnológico, 1978-2006*

\begin{tabular}{|c|c|c|c|c|c|c|}
\hline \multirow[b]{2}{*}{ Año } & \multicolumn{3}{|c|}{ México } & \multicolumn{3}{|c|}{ Corea } \\
\hline & $\begin{array}{c}\text { Sector } \\
\text { moderno }\end{array}$ & $\begin{array}{c}\text { Sector } \\
\text { tradicional }\end{array}$ & Total & $\begin{array}{l}\text { Sector } \\
\text { moderno }\end{array}$ & $\begin{array}{c}\text { Sector } \\
\text { tradicional }\end{array}$ & Total \\
\hline 1978 & 1 & 4 & 5 & 1 & 0 & 1 \\
\hline 1979 & 2 & 8 & 10 & 0 & 2 & 2 \\
\hline 1980 & 2 & 7 & 9 & 0 & 4 & 4 \\
\hline 1981 & 1 & 9 & 10 & 2 & 6 & 8 \\
\hline 1982 & 1 & 7 & 8 & 2 & 0 & 2 \\
\hline 1983 & 3 & 5 & 8 & 2 & 5 & 7 \\
\hline 1984 & 4 & 7 & 11 & 3 & 4 & 7 \\
\hline 1985 & 7 & 5 & 12 & 4 & 17 & 21 \\
\hline 1986 & 5 & 11 & 16 & 7 & 20 & 27 \\
\hline 1987 & 5 & 9 & 14 & 24 & 17 & 41 \\
\hline 1988 & 5 & 13 & 18 & 20 & 20 & 40 \\
\hline 1989 & 3 & 13 & 16 & 32 & 38 & 70 \\
\hline 1990 & 5 & 10 & 15 & 70 & 58 & 128 \\
\hline 1991 & 1 & 4 & 5 & 120 & 91 & 211 \\
\hline 1992 & 4 & 13 & 17 & 175 & 106 & 281 \\
\hline 1993 & 9 & 11 & 20 & 264 & 144 & 408 \\
\hline 1994 & 3 & 18 & 21 & 350 & 168 & 518 \\
\hline 1995 & 13 & 10 & 23 & 443 & 267 & 710 \\
\hline 1996 & 17 & 13 & 30 & 630 & 399 & 1029 \\
\hline 1997 & 21 & 16 & 37 & 837 & 452 & 1289 \\
\hline 1998 & 12 & 20 & 32 & 1239 & 713 & 1952 \\
\hline 1999 & 14 & 16 & 30 & 1412 & 827 & 2239 \\
\hline 2000 & 19 & 25 & 44 & 1474 & 836 & 2310 \\
\hline 2001 & 9 & 44 & 53 & 1706 & 838 & 2544 \\
\hline 2002 & 8 & 36 & 44 & 1912 & 1037 & 2949 \\
\hline 2003 & 23 & 18 & 41 & 2070 & 1109 & 3179 \\
\hline 2004 & 24 & 14 & 38 & 2229 & 1215 & 3444 \\
\hline 2005 & 18 & 18 & 36 & 2217 & 1289 & 3506 \\
\hline 2006 & 16 & 14 & 30 & 2252 & 1347 & 3599 \\
\hline Total & 255 & 398 & 653 & 19497 & 11029 & 30526 \\
\hline
\end{tabular}

* Las diferencias en los totales pueden no coincidir con el original, debido a que un mismo inventor puede participar en más de un año y en más de un campo tecnológico.

FUENTE: Elaboración propia a partir de USPTO (2008). 


\section{REFERENCIAS BIBLIOGRÁFICAS}

Aboites, J., y M. Cimoli, (2002), "Intellectual Property Rights and National Innovation Systems", Revue D'Économie Industrielle, núm. 99, 2do. trimestre 2002, pp. 215-232.

— - y M. Soria (1999), Innovación, propiedad intelectual y estrategias tecnológicas. La experiencia de la economía mexicana, UAM-Xochimilco/Miguel Ángel Porrúa, México.

Antonelli, C., J. L. Gaffard, y M. Quéré (2002), “Interactive Learning and Technological Knowledge: the Localized Character of Innovation Processes", University of Turin in its series Laboratory of Economics, Working Paper, núm. 04/2002, pp. 1-22.

Archibugi y Coco (2004), “A New Indicator of Technological Capabilities for Developed and Developing Countries (ArCo)", World Development, Vol. 32, núm. 4, pp. 629-654.

Banco Mundial (2006), "Korea as a Knowledge Economy: Evolutionary Process and Lessons Learned", editado por Joonghae Suh y Derek H. C. Chen, en: http://web. worldbank.org

Cárdenas, R. (1997), Aspectos tecnológicos de las patentes, Ediciones del Equilibrista, México.

Darby, Michael R., y G. Zucker Lynne (1996), “Star Scientists, Institutions, and the Entry of Japanese Biotechnology Enterprises", NBER Working Paper, núm. 5795, octubre de 1996, pp. 1-44.

David, P. A., y D. Foray (2003), “Una introducción a la economía y a la sociedad del saber", Comercio Exterior, México.

Dogson, M. (1993), "Organizational Learning: A Review of Some Literatures”, Science Policy Research Unit, Vol. 14, núm. 3, pp. 375-394.

Freeman (1982), La teoría económica de la innovación industrial, Alianza Universidad, Madrid.

Gay, C., W. Latham, y C. Le Bas (2005), “Collective Knowledge, Prolific Inventors and the Value of Inventions: An Empirical Study of French, German and British Owned U.S. Patents, 1975-1998”, Working Paper, núm. 2005-16.

Griliches, Z. (1990), "Patent Statistic's as Economic Indicators: A Survey”, Journal of Economic Literature, Vol. 18, núm. 4, diciembre, pp. 1661-1707.

Hall, B., A. Jaffe, y M. Trajtenberg (2001), “The NBER Patent Citation Data File: Lessons, Insights and Methodological Tools", Working Paper, núm. 8498.

Howell, M., y K. Boies (2004), "Champions of Technological Innovation: The Influence of Contextual Knowledge, Role Orientation, Idea Generation, and Idea Promotion on Champion Emergence", The Leadership Quarterly, Vol. 15, pp. 123-143. 
Hu, A., y A. Jaffe (2001), "Patent Citations and International Knowledge Flow: The Case of Korea and Taiwan", National Bureau of Economic Research (NBER), núm. 8528, octubre.

Mangematin, V., S. Lemarié, J. Boissin, D. Catherine, F. Corolleur, R. Coronini, y M. Trommetter (2003), "Development of SMEs and Heterogeneity of Trajectories: The Case of Biotechnology in France", Research Policy, núm. 32, pp. 621-638.

OMPI (2000), "Simposio Internacional: Los Inventores ante el nuevo milenio", Federación Internacional de Organización Mundial de Inventores de la Propiedad Intelectual, septiembre de 2000, en: http://www.wipo.int

- (2005), "La información sobre patentes: un tesoro escondido", Revista de la OMPI, núm. 1, enero-febrero de 2005.

- (2009), “Pequeñas y medianas empresas (Pymes)-Patentes", en: http://www. wipo.int

Pérez, C. (2004), Revoluciones tecnológicas y capital financiero, Siglo XXI, México.

Rojas, B. (2007), “La creatividad e innovación en las organizaciones”, Sapiens. Revista Universitaria de Investigación, año 8, núm. 1, junio, Caracas.

Romer, P. M. (1986), "Increasing Returns and Long-Run Growth", Journal of Political Economy, Vol. 94, núm. 5, pp.1002-1037.

_ , (1990), "Endogenous Technological Change", Journal of Political Economy, Vol. 97, pp. 71-102.

Schmookler, J. (1954), "The level of Inventive Activity”, Review Economic Static, núm. 26. Soonwoo Hong (2008), "La magia de la información sobre patentes", Consejero de la División de Pequeñas y Medianas Empresas (Pymes) de la Organización Mundial de la Propiedad Intelectual (OMPI), pp. 1-8.

Vegara, J. (1985), Ensayos económicos sobre innovación tecnológica, Alianza Editorial, cap. 3, pp.145-162. 